\title{
How to prevent endophthalmitis after intravitreal injections
}

\author{
Roger A Goldberg*
}

\begin{abstract}
Endophthalmitis is an uncommon but often visually devastating complication of intravitreal injections. This commentary reviews the key aspects and technical components of intravitreal injections and how they may relate to the development of endophthalmitis. Because endophthalmitis is a rare event, data are often lacking on specific aspects of injection technique that may or may not be helpful in preventing infection. What is not in doubt, however, is the utmost importance of using povidone-iodine antisepsis to the ocular surface prior to injection, and maintaining a lash and lid margin-free injection site.
\end{abstract}

Keywords: Intravitreal injection, Endophthalmitis, Antisepsis

\section{Background}

Intravitreal injections are routinely performed in a busy vitreoretinal clinic. They are generally safe, but their feared complication-endophthalmitis - can be a visually devastating event. Understanding the key steps to the injection procedure may help minimize the risk of endophthalmitis, and perhaps drive the event rate lower than it currently stands. The aim of this Commentary is to discuss some of these key steps.

\section{Main text}

Intravitreal drug delivery has revolutionized retinal care over the past decade, driven largely by the skyrocketing use of anti-vascular endothelial growth factor (anti-VEGF) agents for the treatment of neovascular age-related macular degeneration (AMD), retinal vein occlusion (RVO), and diabetic macular edema (DME) [1]. These injections are generally safe and well-tolerated, and effective at stabilizing vision in most patients, and improving vision in some patients. One downside to these drugs is their relatively short duration of effect; patients often need frequent, sometimes monthly, injections to maintain visual gains. It is not an uncommon

\footnotetext{
*Correspondence: rgoldberg.eyemd@gmail.com

Bay Area Retina Associates, Walnut Creek, CA 94598, USA
}

scene, then, in a busy vitreoretinal clinic, to see patients receiving their 20th, 30th or even 40th injection.

One challenge this need for repeat injections leads to is an increased likelihood of a patient experiencing a complication of an intravitreal injection over the lifetime of their treatment. The most feared complication of intravitreal injection is endophthalmitis, which can be visually devastating to the affected eye. The rate of endophthalmitis is somewhere between 1 and 2,000-5,000 injections [2], far less than the 1 in 400 rate of post-operative endopthalmitis seen after cataract surgery [3]. However, unlike cataract surgery, which a patient experiences only one time (per eye), an intravitreal injection is a frequently-repeated process, which can transform a low per injection complication rate into a higher per patient complication rate.

Though longer-acting agents may be on the horizon, intravitreal injections will likely be a key component of retinal care for the foreseeable future. Given this reality, how can we, as vitreoretinal specialists, drive the rate of endophthalmitis after intravitreal injection even lower? One prerequisite to answering this question is to fully understand where we are and what we know now. How frequently does infection occur? What are the common causative organisms? What are the critical steps to the procedure? What techniques have been shows to 
be effective-or not effective-at reducing the risk of endophthalmitis?

To this end, Drs. Merani and Hunyor [4] took an important step to answer these questions by summarizing and synthesizing the critical data and expert opinions on endophthalmitis after intravitreal injections. They limit their literature review to published articles on endophthalmitis after intravitreal anti-VEGF injections, and exclude data from clinical trials or from those that include steroid or other non-anti-VEGF injections. Both of these are reasonable decisions. Clinical trials often exclude certain patient populations or mandate protocolspecific injection techniques that may not mimic what happens every day in vitreoretinal clinics. Similarly, the rate of endophthalmitis after intravitreal steroid injections has been reported to be higher than that seen after intravitreal anti-VEGF injections [5], which may be related to the drug, drug vehicle, or patient population and disease states requiring steroid injections.

The authors identified 20 papers that met their inclusion criteria, with each case series having at least 10,000 injections. Over 500,000 injections were pooled, and 144 cases of endophthalmitis were identified. This leads to a rate of $0.028 \%$ [4], which is consistent with previously reported rates.

The reported incidence of endophthalmitis appears to be marginally lower in an operating room-based setting (a common location for intravitreal injections in Europe) versus an office location (where the vast majority of injections occur in the United States) [4]. However, these studies were all retrospective in nature, and it can be difficult to compare the different series. Additionally, the logistical challenges and extensive cost that would be required to shift office-based injections to an operating room would be impractical, at least in the United States.

Would mimicking the operating room environment in the clinic help? In several instances, Merani and Hunyor suggest this may be helpful, though without sufficient evidence to support their recommendation. For example, they suggest that sterile gloves should be worn by the treating clinician, though acknowledge no data exist as to whether gloves at all-let alone sterile gloves-help reduce the rate of endophthalmitis [4]. Similarly, while Wen et al. demonstrated some laboratory simulations of the effect of talking on bacterial growth [6], the use of facemasks specifically, whether worn by the injecting clinician, the technician, or the patient, has not been shown to lower the risk of endophathalmitis. Limiting talking during the procedure may be sufficient.

No data regarding hand antisepsis exists to support one type of hand antisepsis over another, though maintaining good hand hygiene, including the use of alcholol-based agents before and after patient contact, seems to be a good idea. This is the current recommendation for every patient encounter, not just for those receiving intravitreal injections [7].

The package inserts for both ranibizumab (Lucentis, Genentech/Roche, South San Francisco, CA) and aflibercept (Eylea, Regeneron, Tarrytown, NY) state that sterile gloves, drape, and speculum should be used with each injection $[8,9]$. Here again, a paucity of useful data is available to guide us as to whether these three items can help reduce endophthalmitis. Certainly, adequate hand hygiene is required, as is sufficient retraction of the lid margin from the injection site. The lid speculum is often uncomfortable for patients, and manual retraction of the lids is often sufficient to achieve the goal of avoiding eyelid contact with the intended injection site and needle [10].

Merani and Hunyor recommend disinfecting the rubber diaphragm of ranibizumab or aflibercept vials with an alcohol swab immediately before drawing up the medicine into the tuberculin syringe [4]. However, if the metal cap is removed immediately prior to puncturing the vial, with care being taken to avoid touching the rubber diaphragm, this step may be unnecessary, or even harmful. Numerous instances of contaminated alcohol prep pads and swabs have been reported, in some cases leading to nationwide recalls [11].

Ultimately, what is not debated is the paramount importance of topical antisepsis prior to intravitreal injection. For this, povidone iodine solutions are the gold standard. Standard surgical skin preparations are typically $10 \%$ povidone iodine concentration, and include detergents that are toxic and irritating to the ocular surface. Betadine (Alcon Laboratories, Fort Worth, Tx) is a $5 \%$ povidone iodine solution designed for ocular surface anti-sespsis. It can still be irritating and uncomfortable to the ocular surface, even with a pre-treatment anesthetic drop such as proparacaine. It should be applied before any viscous anesthetic gels to achieve adequate antisepsis. Pre- or post-injection antibiotics do not help prevent endophthalmits, and may be harmful by inducing microbial resistance [10].

\section{Conclusion}

Given the projected growth of intravitreal injections [1], we must continue to search for new and better ways to further reduce the rate of endophthalmitis after each injection. Doing so may enable us to drive the per patient rate of infection lower than where it stands today. Though endophthalmitis after intravitreal injection may not be a "never event," [12] we must still strive to do better. 


\section{Abbreviations}

Anti-VEGF: anti-vascular endothelial growth factor; AMD: neovascular agerelated macular degeneration; RVO: retinal vein occlusion; DME: diabetic macular edema.

\section{Compliance with ethical guidelines}

\section{Competing interests}

The author declares that he has no competing interests.

Received: 28 July 2015 Accepted: 30 July 2015

Published online: 11 August 2015

\section{References}

1. Williams GA (2014) IVT injections: health policy implications. Rev Ophthalmol. http://www.reviewofophthalmology.com/content/t/ retina/c/48732/. Accessed 15 July 2015

2. Gregori NZ, Flynn HW Jr, Schwartz SG, Rosenfeld PJ, Vaziri K, Moshfeghi AA et al (2015) Current infectious endophthalmitis rates after intravitreal injections of anti-vascular endothelial growth factor agents and outcomes of treatment. Ophthal Surg Lasers Imaging Retina 46(6):643-648

3. Taban M, Behrens A, Newcomb RL, Nobe MY, Saedi G, Sweet PM, McDonnell PJ et al (2005) Acute endophthalmitis following cataract surgery: a systematic review of the literature. Arch Ophthalmol 123(5):613-620

4. Merani R, Hunyor AP (2015) Endophthalmitis following intravitreal antivascular endothelial growth factor (VEGF) injection-a comprehensive review. Int J Retina Vitreous 1(9)
5. Cheung CS, Wong AW, Lui A, Kertes PJ, Devenyi RG, Lam WC (2012) Incidence of endophthalmitis and use of antibiotic prophylaxis after intravitreal injections. Ophthalmology 119(8):1609-1614

6. Wen JC, McCannel CA, Mochon AB, Garner OB (2011) Bacterial dispersal associated with speech in the setting of intravitreous injections. Arch Ophthalmol 129(12):1551-1554

7. National Center for Emerging and Zoonotic Infectious Diseases, Division of Healthcare Quality Promotion (2014) Hand hygiene basics. Centers for Disease Control and Prevention. http://www.cdc.gov/handhygiene/ Basics.html. Accessed 20 July 2015

8. Genentech (2015) Lucentis highlights of prescribing information. http:// www.gene.com/download/pdf/lucentis_prescribing.pdf. Accessed 20 July 2015

9. Regeneron (2015) Eylea Highlights of Prescribing Information. https:// www.regeneron.com/Eylea/eylea-fpi.pdf. Accessed 20 July 2015)

10. Avery RL, Bakri SJ, Blumenkranz MS, Brucker AJ, Cunningham ET Jr, D’Amico DJ et al (2014) Intravitreal injection technique and monitoring: updated guidelines of an expert panel. Retina. 34(Suppl 12):S1-S18

11. Food and Drug Administration (2011) Triad Group issues a voluntary nationwide recall of all lots of alcohol prep pads, alcohol swabs, and alcohol swabsticks due to potential microbial contamination. US Department of Health and Human Services, Food and Drug Administration, Silver Spring. http://www.fda.gov/safety/recalls/ucm239219.htm. Accessed 14 July 2015

12. Schachat AP, Rosenfeld PJ, Liesegang TJ, Stewart MW (2012) Endophthalmitis is not a "never event". Ophthalmology 119(8):1507-1508

\section{Submit your next manuscript to BioMed Central and take full advantage of:}

- Convenient online submission

- Thorough peer review

- No space constraints or color figure charges

- Immediate publication on acceptance

- Inclusion in PubMed, CAS, Scopus and Google Scholar

- Research which is freely available for redistribution

Submit your manuscript at 